Check for updates

Cite this: RSC Adv., 2018, 8, 11222

\title{
Boron-doped graphene as a metal-free catalyst for gas-phase oxidation of benzyl alcohol to benzaldehyde
}

\author{
Wenjun Cheng, ${ }^{a}$ Xueting Liu, ${ }^{a} \mathrm{Na} \mathrm{Li},{ }^{a}$ Jiatong Han, ${ }^{\mathrm{b}}$ Shuangming $\mathrm{Li}^{\star \mathrm{ac}}$ \\ and Sansan Yu (D) *ac
}

Boron-doped graphene samples (BGs) with tunable boron content of 0-2.90 at\% were synthesized and directly used in the gas-phase oxidation of benzyl alcohol to benzaldehyde, and showed excellent performance. XPS results indicated that the graphitic $\mathrm{sp}^{2} \mathrm{~B}$ species $\left(\mathrm{BC}_{3}\right)$ is the mainly boron dopant species incorporated in the graphene lattice, which could significantly improve the content of ketone carbonyl groups $(\mathrm{C}=\mathrm{O})$ on the graphene. For instance, the contents of $\mathrm{C}=\mathrm{O}$ jumped from 1.93 to 4.19 at\% while $\mathrm{BC}_{3}$ doped into the graphene lattice was only 0.35 at\%. The $\mathrm{C}=\mathrm{O}$ is the active site of catalytic reaction, so BG has significantly improved catalytic activity. Compared to the un-doped graphene (G), the conversion of benzyl alcohol over BGs increased 2.35 times and the selectivity of benzaldehyde increased from $77.3 \%$ to $99.2 \%$. Aerobic-anaerobic exchange experiments revealed that the superior catalytic performance of BG was achieved only under aerobic conditions. The study of the boron-doped carbocatalyst may also provide guidance for the design of surface modified carbon-based catalysts for the selective oxidation dehydrogenation of alcohols by regulating doping elements and their types.

Received 11th January 2018

Accepted 12th March 2018

DOI: $10.1039 / \mathrm{c} 8 \mathrm{ra00290h}$

rsc.li/rsc-advances sustaining efforts have been devoted to choosing the efficient and environmentally catalysts for the oxidation reaction to meet the increasingly stringent ecological standards. ${ }^{\mathbf{1 0 , 1 1}}$

Carbon-based catalysts, including graphene, carbon nanotubes, nanodiamond and other nanocarbon based materials, have attracted great interest in the past decades due to their sustainable development, eco-friendly, high specific surface area, feasible surface modification and continuous largescalable preparation. ${ }^{12-16}$ Additionally, compared to metal based catalysts, carbon based materials provide additional advantages induced by the existence of giant $\pi$ structures in the $\mathrm{sp}^{2}$ hybridization carbon atoms, which promotes strong interactions with various reactants especially for compounds with benzene ring. ${ }^{17}$ In the past several years, significant progress has been made in the study of catalytic performance of the carbon materials. For instance, Zhang et al. reported that carbon nanotubes with modified surface functionality could efficiently catalyze the ODH of $n$-butane to butenes with a high selectivity, which was achieved for periods as long as 100 hours. $^{18}$ Diao et al. used reduced porous graphene oxide as a metal free catalyst for the selective ODH of ethylbenzene to styrene, which showed the best catalytic performance compared with other carbon materials (routinely reduced graphene oxide, graphite powder and oxidized carbon nanotubes) and commercial iron oxide. ${ }^{19}$ Zhang et al. described the application of nano-diamond as a novel catalyst for direct dehydrogenation of ethylbenzene under steam-free conditions. The unique $\mathrm{sp}^{2}-\mathrm{sp}^{3}$ hybrid
${ }^{a}$ College of Chemical Engineering, Shenyang University of Chemical Technology, Shenyang 110142, China. E-mail: ssyu@syuct.edu.cn; lishuangming@syuct.edu.cn; Fax: +8624 89383760; Tel: +862489381190

${ }^{b}$ College of Environmental and Safety Engineering, Shenyang University of Chemical Technology, Shenyang 110142, China

${ }^{c}$ Key Laboratory of Chemical Separation Technology of Liaoning Province, Shenyang University of Chemical Technology, Shenyang 110142, China 


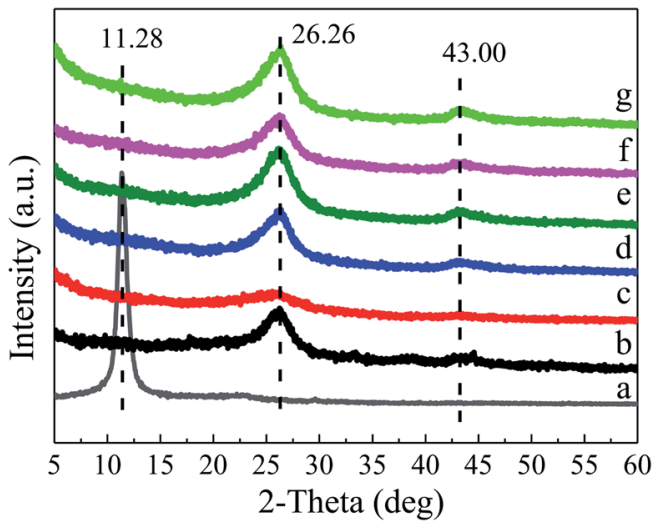

Fig. 1 XRD patterns of (a) GO, (b) G, (c) BG-1, (d) BG-2, (e) BG-3, (f) BG-4 and (g) BG-5.

structure resulted in different behavior to other carbons, with superior activity and stability and freedom from coke formation..$^{20}$

Among these carbon-based materials, graphene, a single layer of $\mathrm{sp}^{2}$-bonded carbon atoms arranged in a hexagonal honeycomb structure, attracts extensive attention in recent years, ${ }^{21}$ due to its unique properties such as good conductivity, ${ }^{22}$ high specific surface area $^{23}$ and high mobility of charge carriers ${ }^{24}$ etc. It is regarded as a promising material for potential application in catalysis. The microstructure and surface chemistry of nanocarbons have been thought to play important role in carbon-catalyzed reactions. For example, $\mathrm{C}=\mathrm{O}$ functional groups, locating at the prismatic edges of stacked graphene sheets or at the surface defects, have been regarded as the active centers for the ODH reactions..$^{53-56}$ Furthermore, heteroatoms doping can offer an effective method to modulate electronic properties and surface physicochemical features of graphene, introduce a considerable amount of defects into the lattice, and promote catalytic performance by introducing electron acceptors or donors. ${ }^{25-30}$

For the chemical doping of graphene, Denis et al. demonstrated that boron and nitrogen atoms are considered to be the best doping elements because their sizes are closed to the carbon atoms, ${ }^{31}$ resulting in strong valence bonds between them. To date, nitrogen-doped graphene (NG) has been applied to organic synthesis reaction. Long et al. reported the NG as metal-free carbon-catalyst applied to selective oxidation of alcohols. ${ }^{21}$ Li et al. prepared NG with different doping contents, which could efficiently catalyze the dehydrogenation of ethanol with $100 \%$ selectivity. ${ }^{32}$ However, BG is mainly applied as electrode material in solar cells and lithium ion batteries. ${ }^{33-36}$ So far, there is no report used BG as catalyst directly for organic synthesis reaction, especially in gas-phase reaction. Theoretical calculations indicate that $\mathrm{O}_{2}$ molecular can be easily adsorbed by boron dopant owing to the large difference of electronegativity between boron and oxygen, which is the precondition for the subsequent formation of $\mathrm{O}^{2-}, \mathrm{O}_{2}{ }^{-}$, and $\mathrm{O}_{2}{ }^{2-} \cdot{ }^{30} \mathrm{In}$ addition, boron can substitute carbon atom at the trigonal sites $\left(\mathrm{BC}_{3}\right),{ }^{37}$ whose electron accepting nature makes boron more affinitive to oxygen compared to carbon. ${ }^{38,39}$ Therefore, we speculate that BG will have certain influence on the oxidation dehydrogenation reaction, compared to $\mathrm{G}$.

Herein, boron-doped graphene was used as catalysts for ODH of benzyl alcohols in order to demonstrate that incorporating boron is a viable method to design efficient carbon-based catalysts for the gas-phase oxidation of benzyl alcohol. Long et al. have been studied NG was used as catalyst for ODH of benzyl alcohol, ${ }^{21}$ what is worth mentioning that the reaction was a liquid-phase-batch reaction. While in this work, BG was used for the gas-phase-continuous reaction. In this study, borondoped graphene samples with tunable boron content of $0-$
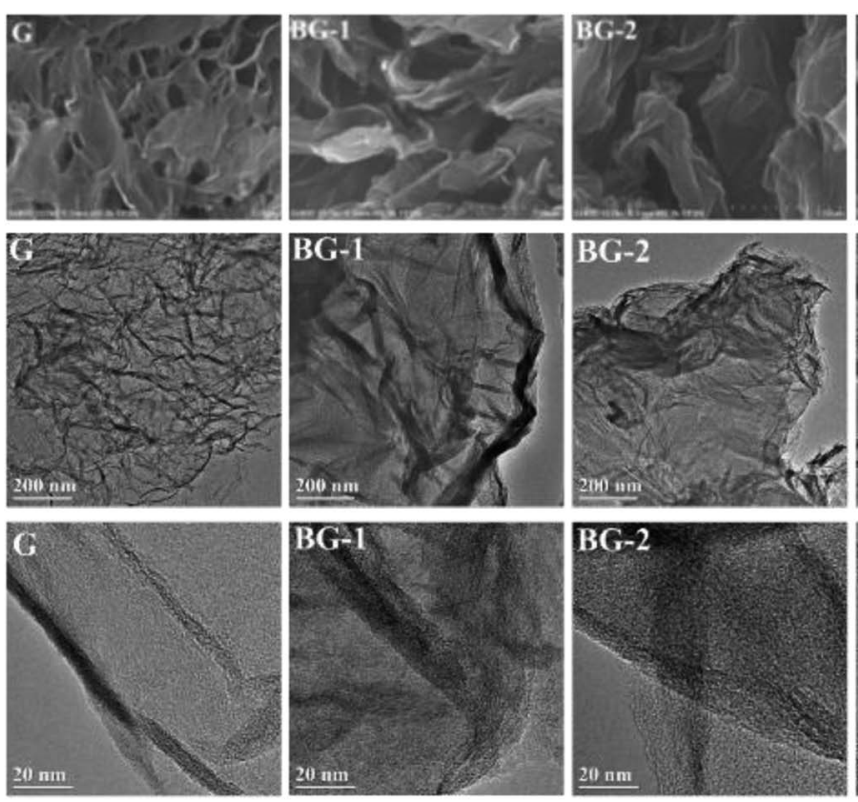
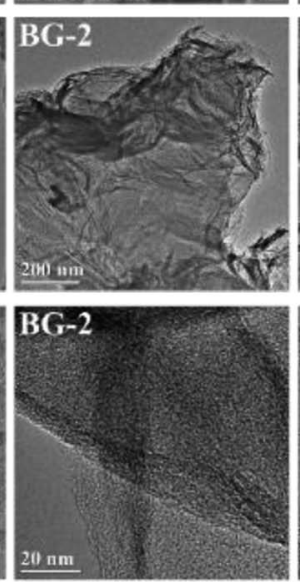
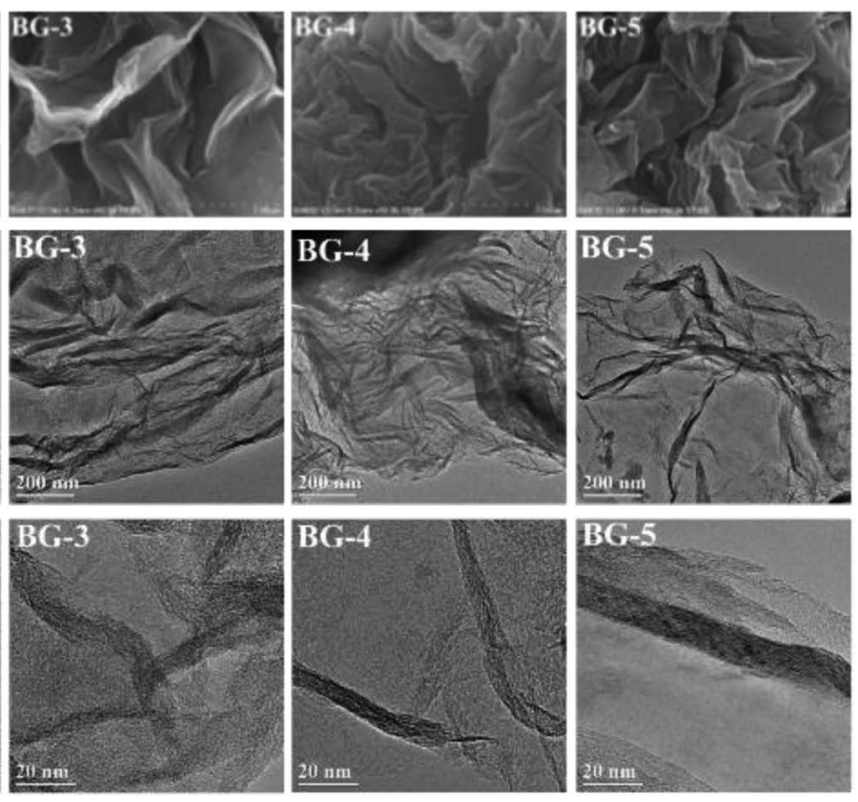

Fig. 2 SEM, TEM and HRTEM images of the boron-doped graphene samples (BGs) and the un-doped graphene (G). 
2.90 at\% were synthesized by regulating the boric acid/ graphene oxide (GO) mass ratio. It was found that the multilayer graphene doped with boron heteroatoms can catalyze oxidative dehydrogenation of benzyl alcohol to benzaldehyde efficiently with the high selectivity.

\section{Experimental section}

\subsection{Preparation of catalysts}

Graphite oxide (GO, purity of 96.0\%) was supplied from Jining Leadernano Technology Co., LTD. (Shandong Province, China).
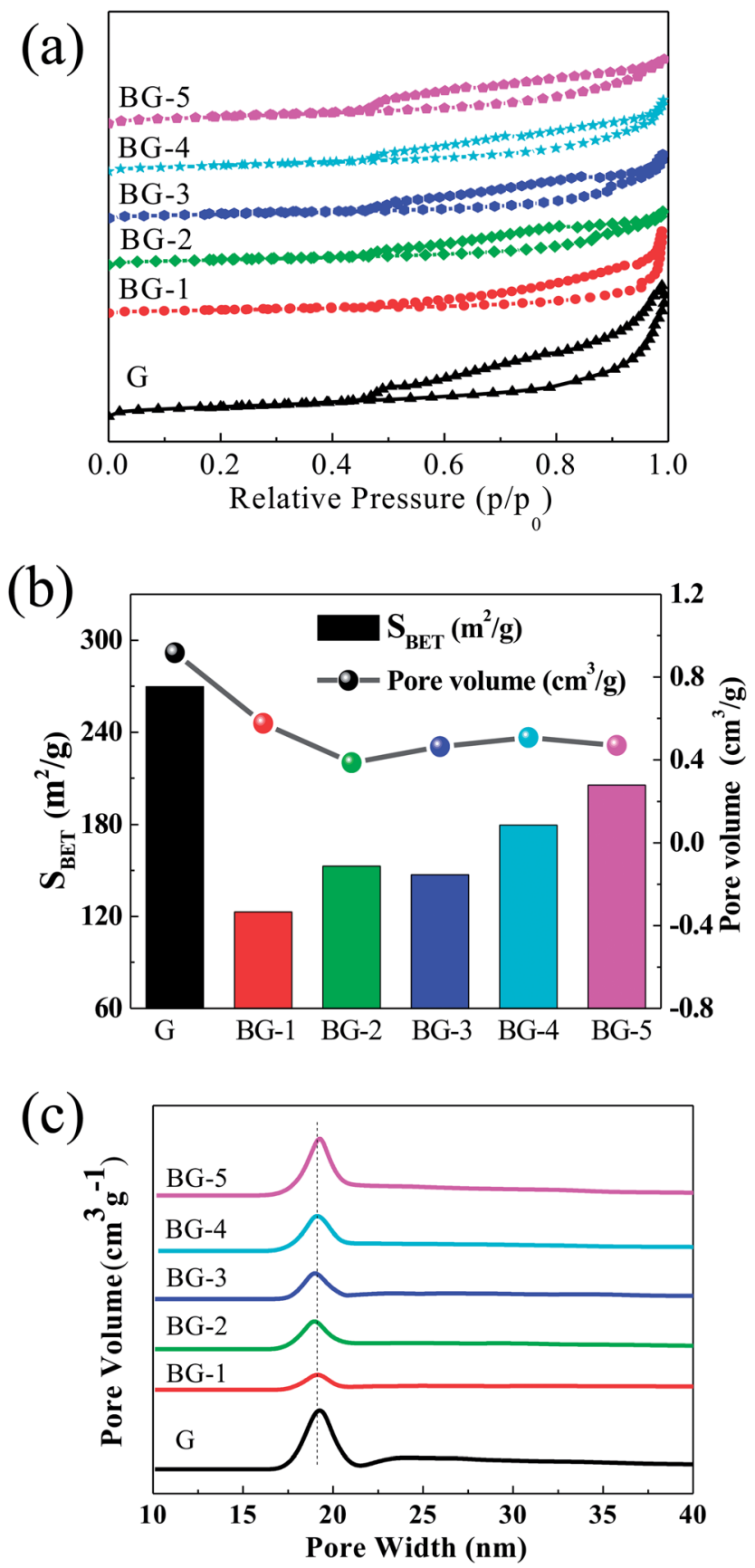

Fig. 3 (a) Nitrogen adsorption-desorption isotherms, (b) specific surface area column (column graph) and pore volume (line graph) and (c) pore size distribution plot.
GO was prepared from natural graphite by a modified Hummers' method. ${ }^{40,41}$ BGs synthesized at $1173 \mathrm{~K}$ were conducted in argon atmosphere for $2 \mathrm{~h}$ with the different mass ratio $(1 / 1,2 / 1,3 / 1,4 / 1$ and $5 / 1)$ of boric acid/GO, and the corresponding products were denoted as BG-1, BG-2, BG-3, BG-4, BG-5. In the typical procedure, GO and boric acid were mixed uniformly in a nickel boat, which was then placed in the center of a corundum tube. The furnace was heated to $1173 \mathrm{~K}$ at a ramping rate of $5 \mathrm{~K} \mathrm{~min}^{-1}$ with a continuous flow of argon, then kept at $1173 \mathrm{~K}$ for $2 \mathrm{~h}$ before cooling down to room temperature naturally. The obtained products were then refluxed in $3 \mathrm{M} \mathrm{KOH}$ aqueous solution for $2 \mathrm{~h}$ to remove the unreacted boron oxide. After filtration and water washing, the samples were dried in a vacuum at $333 \mathrm{~K}$ for overnight. For comparison, $\mathrm{G}$ was prepared by using the same procedure, but neither without adding boric acid nor using $3 \mathrm{M} \mathrm{KOH}$ aqueous solution for reflux washing.

\subsection{Characterizations}

The structure and purity of the products were identified by XRD, which was carried out on a D8 Advance X-ray generator (Bruker AXS Company, Germany) by using $\mathrm{Cu} \mathrm{K} \alpha 1$ radiation. The X-ray intensity was measured over a $2 \theta$ diffraction angle from $5^{\circ}$ to $60^{\circ}$ with a step size of $0.02^{\circ} \mathrm{min}^{-1}$. The morphologies of catalysts were observed by scanning electron microscopy (SEM) (S-4800 FESEM, Hitachi Ltd., Japan) and transmission electron microscopy (TEM) (TECNAI G2 F20, FEI Company, USA). The SEM and TEM images were obtained at an accelerating voltage of 10 and $200 \mathrm{kV}$, respectively. Brunauer-Emmett-Teller (BET) (Autosorb-iQ, Quantachrome, America) surface area analysis was done by nitrogen adsorption-desorption isotherms at liquid nitrogen temperature of $77 \mathrm{~K}$. X-ray photoelectron spectroscopy (XPS) (ESCALAB250, Thermo Electron Corporation, USA) was employed to analyze the surface composition of synthesized materials.

\subsection{Measurement of catalytic performance}

The ODH experiments were carried out at atmospheric pressure using $100 \mathrm{mg}$ of each catalyst in a fixed-bed stainless steel reactor. The reactor was heated at $10 \mathrm{~K} \mathrm{~min}^{-1}$ up to the reaction temperature under $40 \mathrm{~mL} \min ^{-1}$ nitrogen, and after that the feed comprising benzyl alcohol (BA), oxygen $\left(n_{\mathrm{O}_{2}} / n_{\mathrm{BA}}=2\right)$ in nitrogen $\left(n_{\mathrm{N}_{2}} / n_{\mathrm{BA}}=6.2\right)$ was dosed in the reactor at a total flow

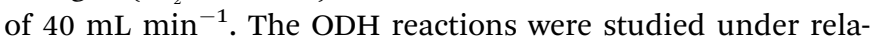
tively gentle conditions (473 and $523 \mathrm{~K}$ ). The liquid-phase product collected after cooling by ice water were sampled periodically and analyzed by High Performance Liquid Chromatography (HPLC, Agilent 1260, USA) equipped with an Agilent Zorbax SB-C18 column. The reaction tail gas was monitored by an on-line Gas Chromatograph (Techcomp GC7980, China) equipped with a thermal conductivity detector (TCD) and a Porapak-Q column. Blank experiments without carbon catalyst showed that reaction conversion were negligible $(<0.2 \%)$. 
(a)

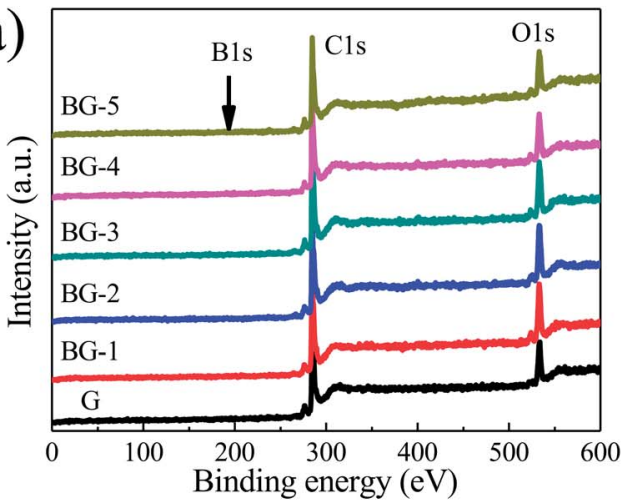

(c)

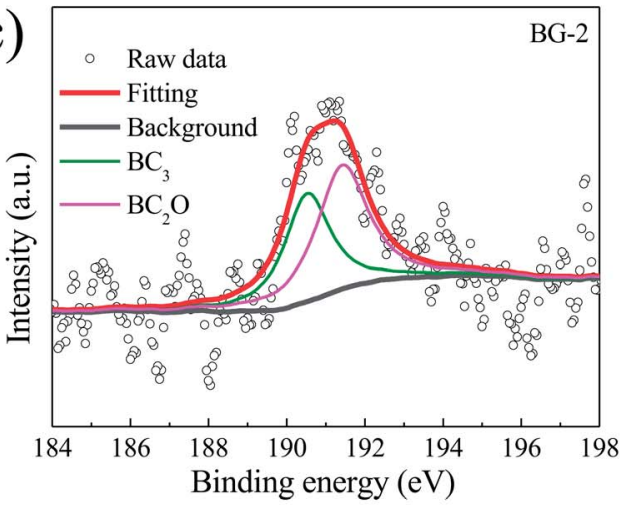

(e)

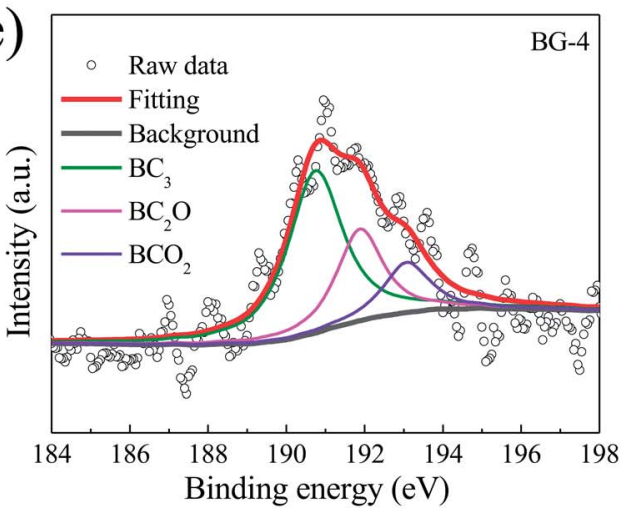

(b)

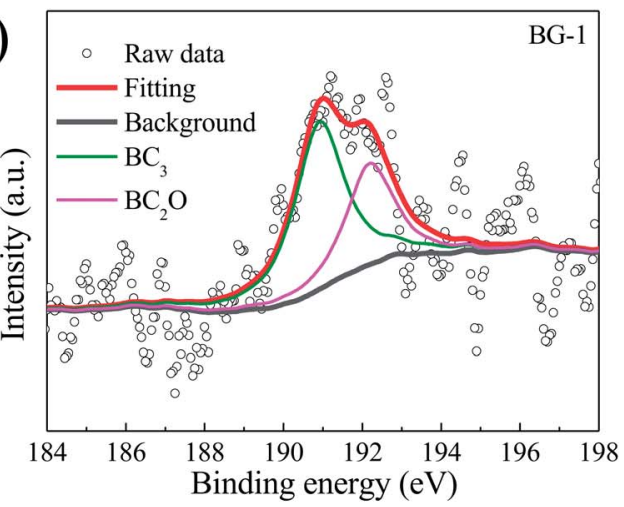

(d)

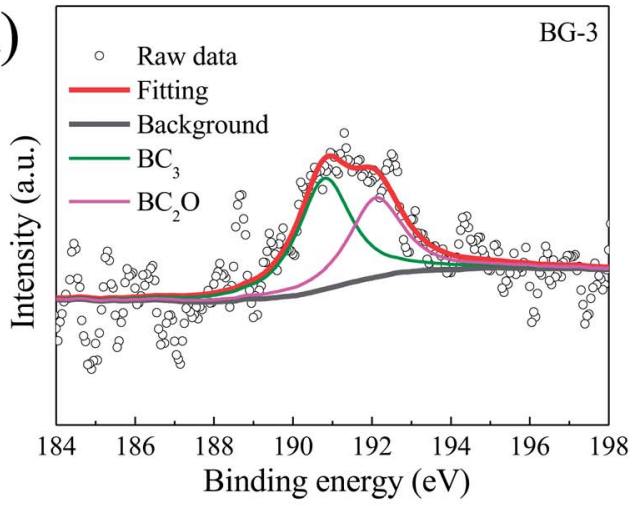

(f)

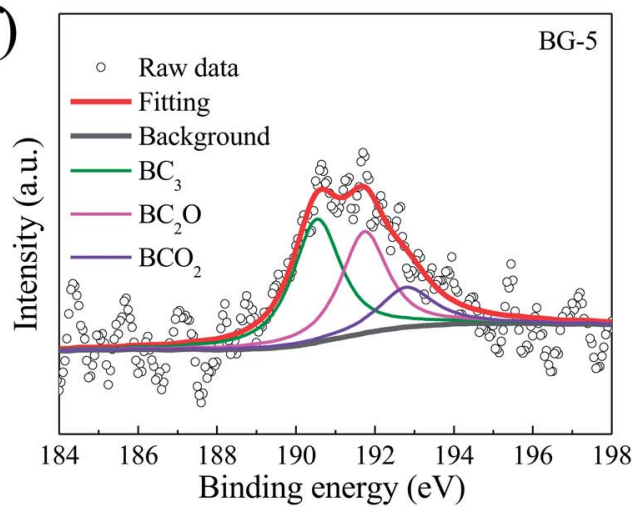

Fig. 4 (a) XPS survey spectrum for the un-doped graphene (G) and BG samples with various boron dopant concentrations, (b)-(f) high resolution $B 1 s$ spectra of the BG samples with various boron dopant concentrations, samples.

Table 1 The deconvolution analysis of carbon functional groups, oxygen functional groups and boron functional groups on these samples

\begin{tabular}{|c|c|c|c|c|c|c|c|c|c|c|}
\hline Sample & $\mathrm{O} / \mathrm{C}^{a}$ & $\mathrm{C}(\mathrm{at} \%)^{b}$ & $\mathrm{O}(\mathrm{at} \%)^{b}$ & B $(\text { at } \%)^{b}$ & \multicolumn{3}{|l|}{$\mathrm{O}$} & \multicolumn{3}{|l|}{ B } \\
\hline BG-1 & 0.24 & 80.26 & 19.19 & 0.55 & 4.19 & 6.65 & 8.35 & 0.35 & 0.20 & - \\
\hline BG-2 & 0.23 & 80.01 & 18.38 & 1.61 & 4.28 & 7.63 & 6.47 & 0.71 & 0.90 & - \\
\hline BG-3 & 0.22 & 80.11 & 17.86 & 2.03 & 4.75 & 5.83 & 7.28 & 1.18 & 0.85 & - \\
\hline
\end{tabular}

${ }^{a}$ The ratio of surface $\mathrm{O}$ and $\mathrm{C}$ content. ${ }^{b}$ Surface carbon, oxygen and boron contents were determined by XPS. ${ }^{c}$ The content of various oxygen species and boron species obtained by deconvolution analysis. 

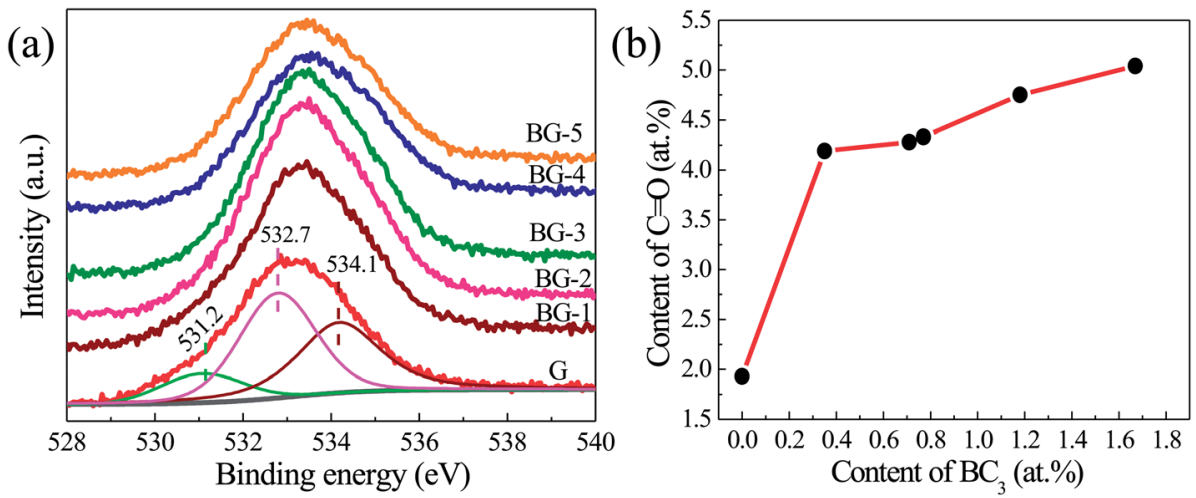

Fig. 5 (a) High resolution O1s spectra of the un-doped graphene (G) and boron-doped graphene samples (BGs) and (b) the relationship between the content of the graphitic $\mathrm{sp}^{2} \mathrm{~B}$ species $\left(\mathrm{BC}_{3}\right)$ and ketone carbonyl groups $(\mathrm{C}=\mathrm{O})$ over different samples.

\section{Results and discussion}

\subsection{Characterization}

3.1.1 XRD. Fig. 1 shows XRD patterns of BGs with different boron doping contents and the un-doped graphene sample. XRD pattern (a) of GO reveals an intense and sharp reflection centered at about $11^{\circ}$, corresponding to a $c$-axis interlayer spacing of $0.81 \mathrm{~nm} .{ }^{21}$ After the thermal processing in Ar atmosphere at $1173 \mathrm{~K}$ for $2 \mathrm{~h}$, the characteristic peak of GO disappears while two broad diffraction peaks at $26.26^{\circ}(d=0.34 \mathrm{~nm})$ and $43.00^{\circ}(d=0.21 \mathrm{~nm})$ appear for G (Pattern b) and BG (Pattern c-g), confirming the successful conversion of GO to graphene. ${ }^{42}$ Furthermore, it suggests that GO cannot be completely and uniformly exfoliated by the interlayer expansion along the $c$-axis direction at such a temperature, leading to the formation of multilayer graphene nanosheets. ${ }^{21}$ The diffraction peaks of the BG with different boron doping contents and $\mathrm{G}$ are very similar, indicating that the boron doping content cannot influence the crystal phase structure of BG.

3.1.2 SEM, TEM and HRTEM. The morphology and microstructure of these as-prepared BGs and G were investigated further by SEM, TEM and HRTEM. As displayed in Fig. 2, all samples exhibit the typical multilayer nanosheets structure of graphene, which is also confirmed by XRD results. Meanwhile, TEM images also indicate that the BGs still remains the nanosheet structure of the G. Both of them can suggest that the two-dimensional structure of BG is efficiently retained after being doped with boron. Moreover, HRTEM characterization further indicates that both of BG samples and $\mathrm{G}$ are the multilayer nanosheets graphene.

3.1.3 BET. Brunauer-Emmett-Teller (BET) specific surface area of BGs and $\mathrm{G}$ were measured at $77 \mathrm{~K}$ from the nitrogen adsorption and desorption isotherms and the results are shown in Fig. 4 . The isotherm profile displays a typical II characteristic with a distinct hysteresis loop observed in the range of $0.45-0.98 p / p_{0}$ (Fig. 3a). G give a specific surface area of $269.71 \mathrm{~m}^{2} \mathrm{~g}^{-1}$ while the specific areas of BGs are from 122.98 to $205.56 \mathrm{~m}^{2} \mathrm{~g}^{-1}$, respectively (Fig. 3b). Barrett-JoynerHalenda (BJH) analysis indicates that the pores are mainly "mesoporous structure" with a pore size distribution of 15$25 \mathrm{~nm}$ centered at about $19 \mathrm{~nm}$ (Fig. 3c). This phenomenon is probably attributed to that GO cannot be completely and uniformly exfoliated by the interlayer expansion at $1173 \mathrm{~K}$, leading to the formation of interspace between the nanosheets. Apparently, the specific surface areas of all samples were much lower than the theoretical value $\left(2630 \mathrm{~m}^{2} \mathrm{~g}^{-1}\right)$ for the graphene, ${ }^{43}$ and this can be attributed to the aggregation of nanosheets under high temperature $(1173 \mathrm{~K}){ }^{\mathbf{4 4}}$

3.1.4 XPS. The survey spectra in Fig. 4a show the presence of carbon, oxygen and boron. GO was annealed in Ar atmosphere at $1173 \mathrm{~K}$, and the obtained G shows a weak O1s signal and no B1s signal in the XPS spectrum (Fig. 4a). After reaction with mixing boric acid at the temperature, the weak B1 signals could be discerned from the XPS spectrum. It shows 2.90 at\% atomic percentage of boron doped in these BG samples. The presence of B1s peak ( $\sim 192 \mathrm{eV})$ instead of the original B peak $(188 \mathrm{eV})$ indicates the incorporation of boron into graphene framework successfully. ${ }^{45}$

In addition, the atomic contents of $\mathrm{C}, \mathrm{O}$, and $\mathrm{B}$ elements in these samples calculated from XPS spectra are summarized in Table 1. Interestingly, it is noted that the oxygen atomic percentage of the BG samples is higher than $\mathrm{G}$ and the oxygen content increases steadily with increasing boron content. Noticeably, the content of boron atoms in the BG samples increases with increasing of the mass ratio of boron acid and GO, and reaches the highest value of $2.90 \%$ for BG-4. Further increasing the mass ration to $5: 1$ does not improve the content of boron in BG, suggesting the boron-doping reaction is completed after increasing the mass ration of $4: 1$. $^{46}$

The effect of the precursors mass ratio on boron species was further analyzed by deconvoluting the B1s spectra. As shown in Fig. 4b-d, the high-resolution B1s peak can be fitted into two peaks centered at 191.28 and $192.60 \mathrm{eV}$, which indicates that there are two types of B species present in these BG nanosheets. However, Fig. 4e-f show that the B1s peak can be fitted into three peaks centered at 191.28 and $192.60 \mathrm{eV}$, and $193.50 \mathrm{eV}$, indicating that there are three types of B species present in BG-4 and BG-5 nanosheets. According to the literatures, ${ }^{21,47,48}$ the binding energies of 191.28, 192.60 and $193.50 \mathrm{eV}$ are attributed to $\mathrm{BC}_{3}, \mathrm{BC}_{2} \mathrm{O}$ and $\mathrm{BCO}_{2}$, respectively. In addition, it can be seen from Table 1 that the $\mathrm{BC}_{3}$ are predominant in these $\mathrm{B}$ species, and a maximum content of 1.67 at $\%$ for $\mathrm{BC}_{3}$ species can be obtained upon the mass ratio at $4: 1$ (BG-4). 
(a)

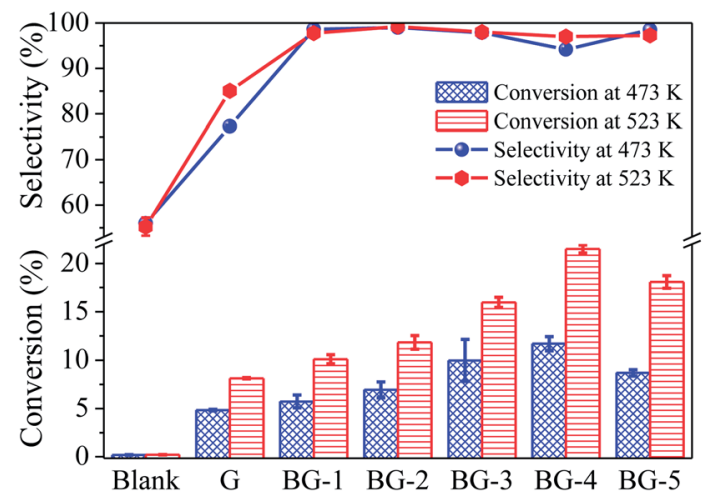

(b)

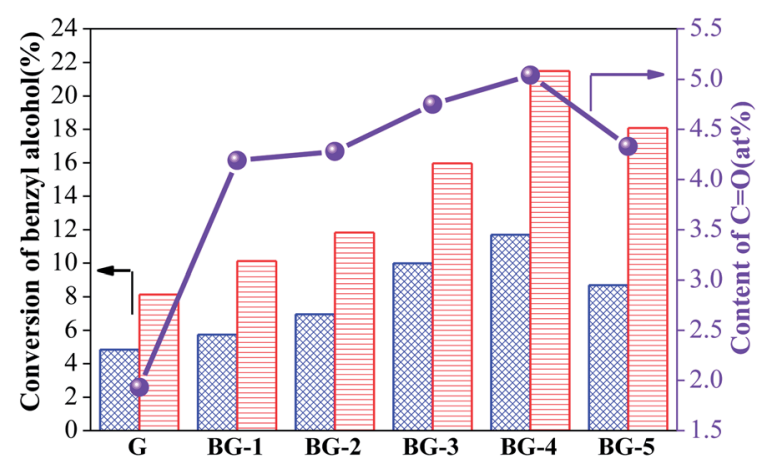

(c)

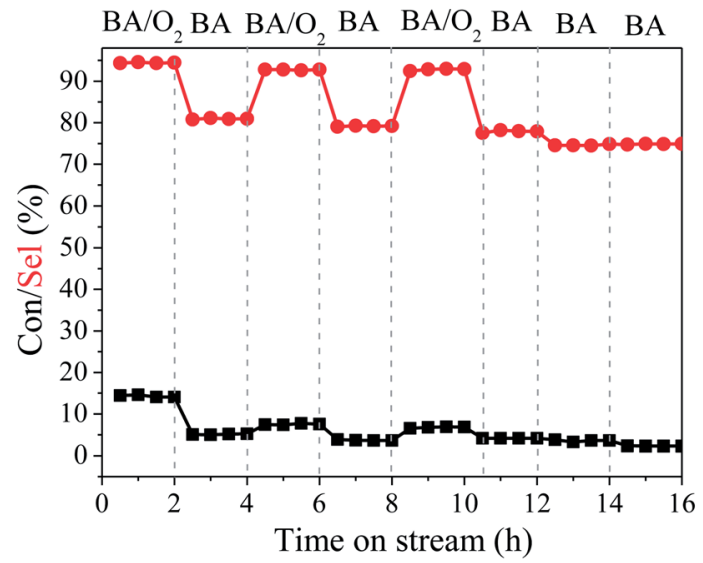

Fig. 6 (a) The conversion of benzyl alcohol (column graph) and the selectivity of benzaldehyde (line graph) over different catalysts at 473 and $523 \mathrm{~K}$, (b) the conversion of benzyl alcohol (column graph) and the content of $\mathrm{C}=\mathrm{O}$ (line graph) over different samples at 473 and523 $\mathrm{K}$, (c) the conversion of benzyl alcohol (column graph) and the selectivity of benzaldehyde (line graph) on aerobic-anaerobic exchange experiments over $\mathrm{BG}-4$ by switching $\mathrm{BA} / \mathrm{N}_{2}$, and $\mathrm{BA} / \mathrm{O}_{2} / \mathrm{N}_{2}$ at $473 \mathrm{~K}$. $\mathrm{BA}=$ $9.0 \%, \mathrm{O}_{2}=18 \%$ with $\mathrm{N}_{2}$ as balance in aerobic conditions, and $\mathrm{BA}=$ $9.0 \%$ with $\mathrm{N}_{2}$ as balance in anaerobic conditions, total flow =

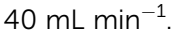

Fig. 5a displays the high-resolution O1s XPS spectra of the BGs and G. The broad O1s peak can be divided into three peaks centered at 531.20, 532.70, and $534.10 \mathrm{eV}$, belonging to $\mathrm{C}=\mathrm{O}$, O$\mathrm{C}=\mathrm{O}$, and $\mathrm{C}-\mathrm{O}-\mathrm{C} / \mathrm{C}-\mathrm{OH}$ groups, respectively. ${ }^{4-52}$ As shown in Fig. $5 \mathrm{~b}$, the contents of $\mathrm{C}=\mathrm{O}$ increase with the boron incorporated in graphene enhancing, indicating that the boron dopant $\left(\mathrm{BC}_{3}\right)$ in the lattice may contribute to the formation of the $\mathrm{C}=\mathrm{O}$ groups.

\subsection{Catalytic performance}

Fig. 6a gives the conversion of benzyl alcohol over BGs with tunable boron content of $0-2.90$ at $\%$ at 473 and $523 \mathrm{~K}$. In the control experiment without catalyst, the conversion of benzyl alcohol detected by HPLC is no more than $0.20 \%$. In the reference experiment with $\mathrm{G}$ as catalyst, the selectivity of benzaldehyde is $77.3 \%(473 \mathrm{~K})$ and $85.1 \%(523 \mathrm{~K})$, which is lower than 94.2-99.2\% of BGs. It is indicated that the introduction of boron could produce benzaldehyde with the high selectivity. As shown in Table 2, results of the selective oxidation of alcohols to aldehydes over different metal-based catalysts and nano-carbon materials reported in recent years are summarized. Although the conversion efficiency of the metal-based catalyst is relatively high, the selectivity (no more than $82 \%$ ) is generally lower than that of the BG and other nano-carbon catalyst (not less than 97\%). Moreover, BGs are compared with other nano-carbon materials in the Table 2. The selectivity of the target products over the BGs and other nano-carbon catalyst are both high, and BGs have advantage in the conversion rate. In addition, the effect of the boron doping in the graphene is the enhancement of the conversion of raw materials. The highest catalytic activity of $11.7 \%(473 \mathrm{~K})$ and $21.5 \%$ (523 K) for the conversion of benzyl alcohol can be obtained upon the boron doping content at 2.90 at\% (BG-4). It can also be seen from the Fig. 6a that the amount of $\mathrm{B}$ doping is different, and the catalytic performance is different. The catalytic activities of the BGs for the aerobic oxidation increase with increasing boron content, for instance, the yield of benzaldehyde enhance from 5.6 to $11.0 \%$ at $473 \mathrm{~K}$ ( 9.9 to $20.9 \%$ at $523 \mathrm{~K}$ ) with the content of boron from 0.55 to 2.90 at\%. The similar changing trend between conversion of benzyl alcohol and the content of $\mathrm{C}=\mathrm{O}$, as shown in Fig. $6 \mathrm{~b}$, indicates the $\mathrm{C}=\mathrm{O}$ groups are the active sites for the $\mathrm{ODH}$ reactions, which is consistent with the literature. ${ }^{\text {20,53-56 }}$ More intuitively, from the Fig. $5 \mathrm{~b}$, the amount of $\mathrm{C}=\mathrm{O}$ increase with the content of $\mathrm{BC}_{3}$ enhancing. Based on these analyses, it was inferred that, doping of boron effectively enhanced the conversion of benzyl alcohol and the selectivity for benzaldehyde production. The $\mathrm{C}=\mathrm{O}$ alone cannot selectively oxidize benzyl alcohol, while only when $\mathrm{BC}_{3}$ and $\mathrm{C}=\mathrm{O}$ are both present, can a high yield of benzaldehyde be achieved.

In addition, aerobic-anaerobic exchanges by switching $\mathrm{BA} / \mathrm{N}_{2}$ and $\mathrm{BA} / \mathrm{O}_{2} / \mathrm{N}_{2}$ at $473 \mathrm{~K}$ experiments were carried out, and the results were as shown in Fig. 6c. About $14.0 \%$ of benzyl alcohol conversion and $94.0 \%$ of benzaldehyde selectivity are obtained under coexistence of benzyl alcohol and oxygen, whereas quick deactivation occurs once oxygen was removed. Fan et al. reported that the lower benzaldehyde yield in the absence of $\mathrm{O}_{2}$ implied oxygen is necessary to shift the equilibrium toward the carbonyl compound and accelerate the reaction. ${ }^{57}$ The reaction occurs without added oxygen supported the so-called classic dehydrogenation mechanism where the alcohol dehydrogenation and oxidant reduction steps are sequential, and not coupled. Therefore, the result convinced us that the superior catalytic performance of boron doped graphene was achieved only under aerobic conditions. 
Table 2 Results of the selective oxidation of alcohols to aldehydes over different traditional catalyst and nano-carbon materials reported in the literature

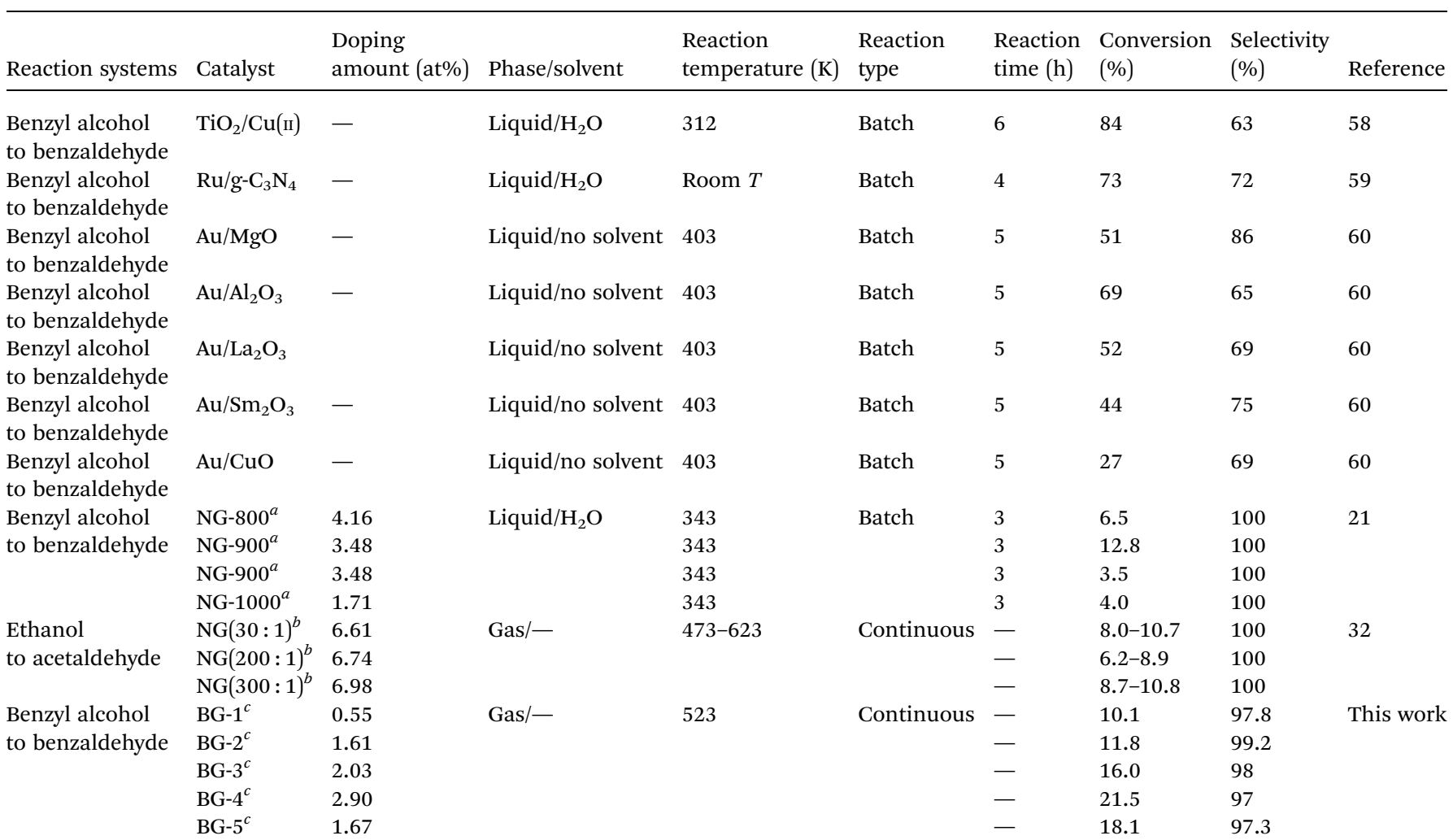

${ }^{a}$ The three N-doped graphene samples were denoted as NG-T, where $T$ means nitridation temperature. ${ }^{b}$ The NG $(x: 1)$ means the nitrogen-doped graphene with different nitrogen doping contents, where $x: 1$ means a mass ratio between urea and graphite oxide (GO). ${ }^{c}$ Boron-doped graphene samples were synthesized with the different mass ratio (1/1,2/1,3/1, 4/1 and 5/1) of boric acid/GO and the corresponding products were denoted as BG-1, BG-2, BG-3, BG-4 and BG-5.

\section{Conclusions}

In summary, we study surface physical and chemical property of BGs and G and their catalytic performance in the gas-phase oxidation benzyl alcohol to benzaldehyde, which thoroughly revealing how the BGs enhanced the performance in the $\mathrm{ODH}$ reaction. The effect of the boron doping in the graphene is the enhancement of the conversion of benzyl alcohol and the selectivity of benzaldehyde. The superior catalytic performance of BGs is attributed to boron doping species $\left(\mathrm{BC}_{3}\right)$ enhanced the $\mathrm{O}_{2}$ chemisorption on catalysts and further promoted forming the active sites $(\mathrm{C}=\mathrm{O})$. It can be observed with XPS analysis, the $\mathrm{BC}_{3}$ could stimulate the increase in the amount of $\mathrm{C}=\mathrm{O}$ obviously, and thus promoted the $\mathrm{C}-\mathrm{H}$ bond activation ability of BG. This study provides a direction to the heteroatom doped on the graphene for the oxidative dehydrogenation reaction of benzyl alcohol. We anticipate that the heteroatom doped on the surface microstructure of graphene can open a new and fascinating route for designing highly efficient nanocarbon catalysts.

\section{Conflicts of interest}

There are no conflicts to declare.

\section{Acknowledgements}

This work was partially supported by Liaoning BaiQianWan Talents Program, China (No. 2013921046), and Natural Science Foundation of Liaoning Province, China (No. 2015020245 and 20170540714).

\section{References}

1 R. A. Sheldon, I. W. C. E. Arends, G. T. Brink and A. Dijksman, Acc. Chem. Res., 2002, 35, 774-781.

2 R. A. Sheldon, I. W. C. E. Arends and A. Dijksman, Catal. Today, 2000, 57, 157-166.

3 A. Dijksman, A. Marinogonzalez, A. M. I. Payeras, A. I. W. C. E. Arends and R. A. Sheldon, J. Am. Chem. Soc., 2001, 123, 6826-6833.

4 Z. Du, J. Ma, H. Ma, M. Wang, Y. Huang and J. Xu, Catal. Commun., 2010, 11, 732-735.

5 Z. Du, J. Ma, H. Ma, J. Gao and J. Xu, Green Chem., 2010, 12, 590-592.

6 T. F. Blackburn and J. Schwartz, Chem. Commun., 1977, 157158.

7 M. J. Schultz, R. S. Adler, W. Zierkiewicz, T. Privalov and M. S. Sigman, J. Am. Chem. Soc., 2005, 127, 8499-8507. 
8 M. Lee and S. Chang, Tetrahedron Lett., 2000, 41, 7507-7510. 9 J. Gross, K. Tauber, M. Fuchs, N. G. Schmidt, A. Rajagopalan, K. Faber, W. M. F. Fabian, J. Pfeffer, T. Haas and W. Kroutil, Green Chem., 2014, 16, 2117-2121.

10 D. S. Mannel, S. S. Stahl and T. W. Root, Org. Process Res. Dev., 2014, 18, 1503-1508.

11 M. J. Schultz and M. S. Sigman, Tetrahedron, 2006, 62, 82278241.

12 C. Su and K. P. Loh, Acc. Chem. Res., 2013, 46, 2275-2285.

13 S. Navalon, A. Dhakshinamoorthy, M. Alvaro and H. Garcia, Chem. Rev., 2014, 114, 6179-6212.

14 X. Fan, G. Zhang and F. Zhang, Chem. Soc. Rev., 2015, 44, 3023-3035.

15 H. Hu, J. H. Xin, H. Hu, X. Wang and Y. Kong, Appl. Catal., A, 2015, 492, 1-9.

16 D. S. Su, S. Perathoner and G. Centi, Chem. Rev., 2013, 113, 5782-5816.

17 P. Serp and J. L. Figueiredo, Carbon materials for catalysis, John Wliey \& Sons, Hoboken, New Jersey and Canada, 2009, pp. 20-23.

18 J. Zhang, X. Liu, R. Blume, A. Zhang, R. Schlogl and D. S. Su, Science, 2008, 322, 73-77.

19 J. Diao, H. Liu, J. Wang, Z. Feng, T. Chen, C. Miao, W. Yang and D. S. Su, Chem. Commun., 2015, 51, 3423-3425.

20 J. Zhang, D. S. Su, R. Blume, R. Schlogl, R. Wang, X. Yang and A. Gajovic, Angew. Chem., Int. Ed. Engl., 2010, 49, 8640-8644.

21 J. Long, X. Xie, J. Xu, Q. Gu, L. Chen and X. Wang, ACS Catal., 2012, 2, 622-631.

22 A. A. Balandin, S. Ghosh, W. Bao, I. Calizo, D. Teweldebrhan, F. Miao and C. N. Lau, Nano Lett., 2008, 8, 902-907.

23 M. D. Stoller, S. J. Park, Y. W. Zhu, J. H. An and R. S. Ruoff, Nano Lett., 2008, 8, 3498-3502.

24 D. R. Dreyer, R. S. Ruoff and C. W. Bielawski, Angew. Chem., 2010, 49, 9336-9344.

25 H. Liu, Y. Liu and D. Zhu, J. Mater. Chem., 2011, 21, 33353345.

26 M. Pumera and C. H. A. Wong, Chem. Soc. Rev., 2013, 42, 5987-5995.

27 B. Guo, Q. Liu, E. Chen, H. Zhu, L. Fang and J. R. Gong, Nano Lett., 2010, 10, 4975-4980.

28 D. Geng, S. Yang, Y. Zhang, J. Yang, J. Liu, R. Li, T.-K. Sham, X. Sun, S. Ye and S. Knights, Appl. Surf. Sci., 2011, 257, 91939198.

29 R. Lv and M. Terrones, Mater. Lett., 2012, 78, 209-218.

30 L. Yang, S. Jiang, Y. Zhao, L. Zhu, S. Chen, X. Wang, Q. Wu, J. Ma, Y. Ma and Z. Hu, Electrocatalysis, 2011, 50, 7132-7135.

31 P. A. Denis and C. Pereyra Huelmo, Carbon, 2015, 87, 106115.

32 S. Li, W. Wang, X. Liu, X. Zeng, W. Li, N. Tsubaki and S. Yu, RSC Adv., 2016, 6, 13450-13455.

33 Z. Sheng, H. Gao, W. Bao, F. Wang and X. Xia, J. Mater. Chem., 2012, 22, 390-395.

34 T. Lin, F. Huang, J. Liang and Y. Wang, Energy Environ. Sci., 2011, 4, 862-865.
35 X. Li, L. Fan, Z. Li, K. Wang, M. Zhong, J. Wei, D. Wu and H. Zhu, Adv. Energy Mater., 2012, 2, 425-429.

36 Z. Wu, W. Ren, L. Xu, F. Li and H. Cheng, ACS Nano, 2011, 5, 5463-5471.

37 D. W. Wang, F. Li, Z. G. Chen, G. Q. Lu and H. M. Cheng, Chem. Mater., 2008, 20, 7195-7200.

38 P. A. Denis, C. P. Huelmo and F. Iribarne, Comput. Theor. Chem., 2014, 1049, 13-19.

39 P. A. Denis and F. Iribarne, Chem. Phys. Lett., 2016, 658, 152157.

40 H. Kim, M. Seo, M. H. Park and J. Cho, Angew. Chem., Int. Ed. Engl., 2010, 49, 2146-2149.

41 C. Zhu, S. Guo, Y. Fang and S. Dong, ACS Nano, 2010, 4, 2429-2437.

42 L. Tang, Y. Wang, Y. Li, H. Feng, J. Lu and J. Li, Adv. Funct. Mater., 2009, 19, 2782-2789.

43 H. Guo, M. Peng, Z. Zhua and L. Suna, Nanoscale, 2013, 5, 9040-9048.

44 L. Niu, Z. Li, W. Hong, J. Sun, Z. Wang, L. Ma, J. Wang and S. Yang, Electrochim. Acta, 2013, 108, 666-673.

45 L. Wang, Y. Ye, X. Lu, Z. Wen, Z. Li, H. Hou and Y. Song, Sci. Rep., 2013, 3, 3568.

46 T. Kwon, H. Nishihara, H. Itoi, Q. Yang and T. Kyotani, Langmuir, 2009, 25, 11961-11968.

47 C. H. Choi, S. H. Park and S. I. Woo, ACS Nano, 2012, 6, 70847091.

48 Z. Wu, A. Winter, L. Chen, Y. Sun, A. Turchanin, X. Feng and K. Mullen, Adv. Mater., 2012, 24, 5130-5135.

49 D. Yang, A. Velamakanni, G. Bozoklu, S. Park, M. D. Stoller, R. D. Piner, S. Stankovich, I. Jung, D. Field, C. Ventrice and R. S. Ruoff, Carbon, 2009, 47, 145-152.

50 D. Long, W. Li, L. Ling, J. Miyawaki, I. Mochida and S. Yoon, Langmuir, 2010, 26, 16096-16102.

51 R. Arrigo, M. Hävecker, S. Wrabetz, R. Blume, M. Lerch, J. McGregor, E. P. J. Parrott, J. A. Zeitler, L. F. Gladde, A. Knop-Gericke, R. Schlögl and D. S. Su, J. Am. Chem. Soc., 2010, 132, 9616-9630.

52 L. Shi, W. Qi, W. Liu, P. Yan, F. Li, J. Sun and D. Su, Catal. Today, 2017, 301, 48-54.

53 J. Zhang, X. Liu, R. Blume, A. Zhang, R. Schlogl and D. S. Su, Science, 2008, 322, 73-77.

54 Y. Zhang, R. Huang, Z. Feng, H. Liu, C. Shi, J. Rong, B. Zong and D. Su, J. Energy Chem., 2016, 25, 349-353.

55 W. Qi, W. Liu, X. Guo, R. Schlogl and D. Su, Angew. Chem., Int. Ed. Engl., 2015, 54, 13682-13685.

56 J. Wang, R. Huang, Z. B. Feng, H. Y. Liu and D. S. Su, Chemsuschem, 2016, 9, 1820-1826.

57 Y. Dai, X. Yan, Y. Tang, X. Liu, L. Xiao and J. Fan, ChemCatChem, 2012, 4, 1603-1610.

58 L. d. P. P. R. D. Spasiano, J. C. Olleros, S. Malato, R. Marotta and R. Andreozzi, Appl. Catal., B, 2013, 56-63.

59 M. J. Lima, P. B. Tavares, A. M. T. Silva, C. G. Silva and J. L. Faria, Catal. Today, 2017, 287, 70-77.

60 V. R. Choudhary, A. Dhar, P. Jana, R. Jha and B. S. Uphade, Green Chem., 2005, 7, 768. 